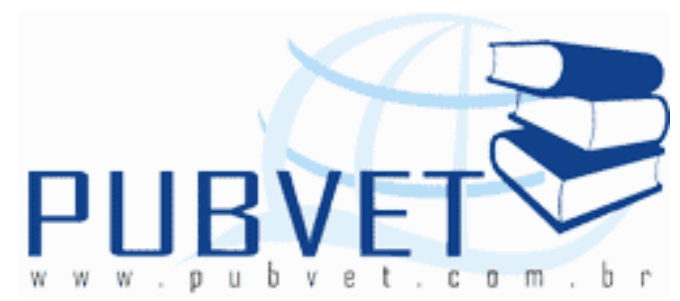

PUBVET, Publicações em Medicina Veterinária e Zootecnia.

\title{
Utilização de antioxidantes nas rações
}

Sabrina Marcantonio Coneglian ${ }^{1}$, Beatriz da Silva Lima², Lorrayny Galoro da Silva $^{3}$, Claudia Mara Lazzari ${ }^{4}$, Román David Castañeda Serrano ${ }^{5}$, Cleiton Luiz Tonello ${ }^{6}$

1 Doutora em Nutrição Animal pela Universidade Estadual de Maringá. Email: sa zootecnia@hotmail.com

2 Graduanda em Zootecnia - Universidade Estadual de Maringá.

3 Mestranda em Zootecnia - Universidade Estadual de Maringá.

4 Zootecnista formada pela Universidade Estadual de Maringá.

5 Médico Veterinário e Zootecnista, Doutorando em Zootecnia - Universidade Estadual de Maringá.

${ }^{6}$ Doutorando em Zootecnia - Universidade Estadual de Maringá.

\section{Resumo}

Para assegurar que nutrientes sejam ingeridos, digeridos, protegidos da destruição, absorvidos e transportados às células do organismo, incluímos na dieta certos aditivos, na sua maioria, não nutritivos, com a finalidade de um melhor balanceamento dos nutrientes do alimento. Alguns aditivos são encontrados na natureza. Outros aditivos são produzidos por síntese, mas são idênticos aos encontrados na natureza, e outros, ainda, são 
CONEGLIAN, S.M. et al. Utilização de antioxidantes nas rações. PUBVET, Londrina, V. 5, N. 5, Ed. 152, Art. 1026, 2011.

fabricados por cientistas de alimentos e não são baseados em substâncias que ocorrem naturalmente. Os antioxidantes, segundo U.S.F.D.A. (United State Food and Drug Administration), são definidos como substâncias empregadas para preservar alimentos por retardar deteriorização, rancidez ou descoloração devido a oxidação. Os principais oxidantes naturais, amplamente utilizados, são os tocoferóis (vitamina E) e o ácido ascórbico (vitamina C).

Palavras-chave: aditivos, rancidez oxidativa, vitaminas.

\title{
Use of antioxidants in diets
}

\begin{abstract}
To ensure that nutrients are ingested, digested, protected from destruction, absorbed and transported to body cells, include certain additives in the diet, mostly non-nutritive, aiming at a better balance of nutrients from food. Some additives are found in nature. Other additives are produced by synthesis, but are identical to those found in nature, and still others are made by food scientists and are not based on naturally occurring substances. Antioxidants, second U.S.F.D.A. (United State Food and Drug Administration) are defined as substances used to preserve food by retarding deterioration, rancidity or discoloration due to oxidation. The main natural antioxidant, widely used, are the tocopherols (vitamin E) and ascorbic acid (vitamin C).
\end{abstract}

Keywords: additives, oxidative rancidity, vitamins.

\section{INTRODUÇÃO}

A alimentação corresponde 60 a $70 \%$ dos custos da produção animal, pois ela necessita ter níveis adequados de nutrientes para explorar a melhor 
CONEGLIAN, S.M. et al. Utilização de antioxidantes nas rações. PUBVET, Londrina, V. 5, N. 5, Ed. 152, Art. 1026, 2011.

capacidade do animal e alcançar sua lucratividade. Para assegurar que estes nutrientes sejam ingeridos, digeridos, protegidos da destruição, absorvidos e transportados às células do organismo, incluímos na dieta certos aditivos, na sua maioria, não nutritivos, com a finalidade de um melhor balanceamento dos nutrientes do alimento.

Por causa da globalização, as exigências dos mercados consumidores ampliaram-se, visando a saúde humana, criando determinadas regras para o uso destes aditivos na alimentação animal, e anualmente estas regras mudam restringindo a utilização de alguns.

\section{O QUE SÃO ADITIVOS?}

São substâncias adicionada ao alimento, com a finalidade de conservar, intensificar ou modificar suas propriedades, desde que não prejudique o seu valor nutritivo.

A maioria dos alimentos processados (manufaturados ou industrializados), contém aditivo alimentar. Existem cerca de 3.500 aditivos usados universalmente pelas indústrias. Não há razão para chamá-los de "produtos químicos", pois tudo, do ar à água, é constituído de muitos milhares de "produtos químicos".

Alguns aditivos são encontrados na natureza. Outros aditivos são produzidos por síntese, mas são idênticos aos encontrados na natureza, e outros, ainda, são fabricados por cientistas de alimentos e não são baseados em substâncias que ocorrem naturalmente.

\section{CONTROLE PELA LEGISLAÇÃo}

A legislação proíbe colocar nos alimentos qualquer coisa que possa prejudicar a saúde. Os departamentos do Ministério da Saúde 
CONEGLIAN, S.M. et al. Utilização de antioxidantes nas rações. PUBVET, Londrina, V. 5, N. 5, Ed. 152, Art. 1026, 2011.

decidem o que pode ser adicionado aos alimentos, com segurança para a saúde do consumidor.

Os aditivos têm de passar por longos e minuciosos exames antes de serem liberados para uso geral.

Sob o ponto de vista médico, os aditivos são seguros e não causam nenhum mal à saúde, para a maioria dos consumidores. Pouquíssimas pessoas apresentam reação a aditivos, da mesma forma como existem pouquíssimas pessoas alérgicas a determinados alimentos, como morangos, crustáceos (camarões, lagostas, caranguejos, etc.). Na verdade, existem mais pessoas alérgicas a substâncias naturais do que a aditivos fabricados.

Cerca de 3.500 aditivos estão em uso atualmente. Todos os aditivos permitidos são considerados seguros e necessários e são controlados por lei. Os aditivos para alimentos devem ser aprovados antes de poderem ser utilizados na produção de alimentos.

Dá-se letra E, seguida de um número, aos aditivos permitidos. Alguns aditivos têm um número sem o prefixo $E$, pois estão sendo examinados para serem licenciados pelo órgão legislador. Todos os rótulos de alimentos devem mostrar o nome do aditivo ou o seu número E na lista dos ingredientes.

\section{ANTIOXIDANTES}

Os antioxidantes, segundo U.S.F.D.A. (United State Food and Drug Administration), são definidos como substâncias empregadas para preservar alimentos por retardar deteriorização, rancidez ou descoloração devido a oxidação. Os antioxidantes têm sido descritos como substâncias que atuam como inibidores de radicais livres, interferindo no mecanismo de autoxidação de lipídeos (DECKER \& XU, 1998). 
CONEGLIAN, S.M. et al. Utilização de antioxidantes nas rações. PUBVET, Londrina, V. 5, N. 5, Ed. 152, Art. 1026, 2011.

Há vários compostos que são utilizados como antioxidantes de grau alimentar, tais como, aqueles que exercem a função de seqüestradores de radicais livres, absorventes de oxigênio e quelantes. Os principais antioxidantes sintéticos são compostos fenólicos, como BHA (hidroxianisol butilado), BHT (hidroxitolueno butilado), TBHQ (terc-butil hidroquinona), e PG (galato de propila). Estes são denominados de antioxidantes primários, atuando na etapa da iniciação da oxidação lipídica. Os antioxidantes sintéticos, por motivo de risco potencial à saúde humana, vêm sendo substituídos por antioxidantes naturais provenientes de várias fontes vegetais, considerados mais seguros à saúde.

Os principais oxidantes naturais, amplamente utilizados, são os tocoferóis (vitamina E) e o ácido ascórbico (vitamina C). A vitamina E é considerada um antioxidante e atua na etapa de propagação e terminação da oxidação lipídica, reagindo com os radicais livres e/ou seqüestrando a molécula de oxigênio. $O$ ácido ascórbico, assim como os ácidos cítrico e fítico, atuam na oxidação lipídica como agentes quelantes ou seqüestrantes e são considerados antioxidantes secundários.

O ácido fítico está presente em muitos vegetais, cereais e leguminosas e tem sido utilizado como antioxidante em alguns sistemas alimentares. A sua ação antioxidante está relacionada com a propriedade de formar quelato com o ferro, tornando-o cataliticamente inerte (GRAF \& EATON, 1990; EMPSON et al., 1991; ZHOU \& ERDMAN, 1995).

\section{MECANISMO DA RANCIDEZ OXIDATIVA}

A rancidez oxidativa é iniciada pelo ataque do oxigênio molecular às duplas ligações dos ácidos graxos insaturados que compõe um lipídeo.

Este processo ocorre somente em condições extremas, altas temperaturas e/ou pressão, uma vez que oxigênio molecular é quimicamente pouco reativo. 
CONEGLIAN, S.M. et al. Utilização de antioxidantes nas rações. PUBVET, Londrina, V. 5, N. 5, Ed. 152, Art. 1026, 2011.

A estrutura eletrônica do oxigênio permite receber ou eliminar elétrons, gerando em sua estrutura um desarranjo eletrônico que converte a molécula de oxigênio em um radical livre de alta reatividade química (radicais livres superóxido e hidróxilo), que necessitam de catalisadores para favorecer o processo. Os catalisadores mais importantes são os metais, especialmente os de valência +2 ( $\mathrm{Fe}, \mathrm{Cu}, \mathrm{Ni}, \mathrm{Co}, \mathrm{Cd}$ e $\mathrm{Zn}$ ) em estado livre como íons, ligados a estrutura inorgânica (complexos metálicos) ou estruturas orgânicas unidas a proteínas, tais como o Fe da hemoglobina.

O efeito catalisador dos metais é facilitado por temperatura, pressão, luz solar ou artificial e em uma forma muito importante, que é a concentração de oxigênio.

A presença de microorganismos também pode facilitar o desenvolvimento da rancidez oxidativa pelo efeito de enzimas ou outras moléculas que facilitam a formação de radicais livres de oxigênio, que podem atacar a molécula do ácido graxo insaturado, que se converte em um radical livre de alta reatividade que pode ser atacado pelo oxigênio molecular, gerando pela adição do oxigênio ao ácido graxo, diferentes produtos intermediários tais como peróxidos, alcoóxidos, epóxidos, etc, que para estabilizarem-se subtraem hidrogênio de outros ácidos graxos não atacados por radicais livres de oxigênio, transformando-os em radicais livres de ácidos graxos.

Esta etapa é conhecida como fase de propagação e o processo de rancidez é autocatalítico e não necessita da participação dos radicais livres do oxigênio que começaram a fase inicial, também denominada de período de indução.

$\mathrm{Na}$ fase de propagação, o processo oxidativo é rápido e acompanhado de alto consumo de oxigênio, caracterizando-se por drásticas mudanças estruturais dos lipídeos. O grau de insaturação dos ácidos graxos que compõem os lipídeos é crucial nesta etapa e quanto mais poliinsaturação apresenta o lipídeo, mais susceptível e rápida será a rancidez oxidativa. É por este fato que os óleos, 
CONEGLIAN, S.M. et al. Utilização de antioxidantes nas rações. PUBVET, Londrina, V. 5, N. 5, Ed. 152, Art. 1026, 2011.

devido sua maior proporção de ácidos graxos insaturados, são mais susceptíveis que as gorduras para iniciar e desenvolver a rancidez oxidativa e as transformações moleculares pelas quais passam os lipídeos durante esta fase, dando origem, a partir da ruptura molecular, produtos (alguns potencialmente tóxicos) conhecidos como aldeídos, cetonas, peróxidos, hidroperóxidos, além de hidrocarbonetos (alifáticos e aromáticos), de baixo peso molecular, voláteis e que dão origem ao típico sabor ou odor de ranço de uma substância oxidada, esta então chamada de fase terminal (Figura 1 ).

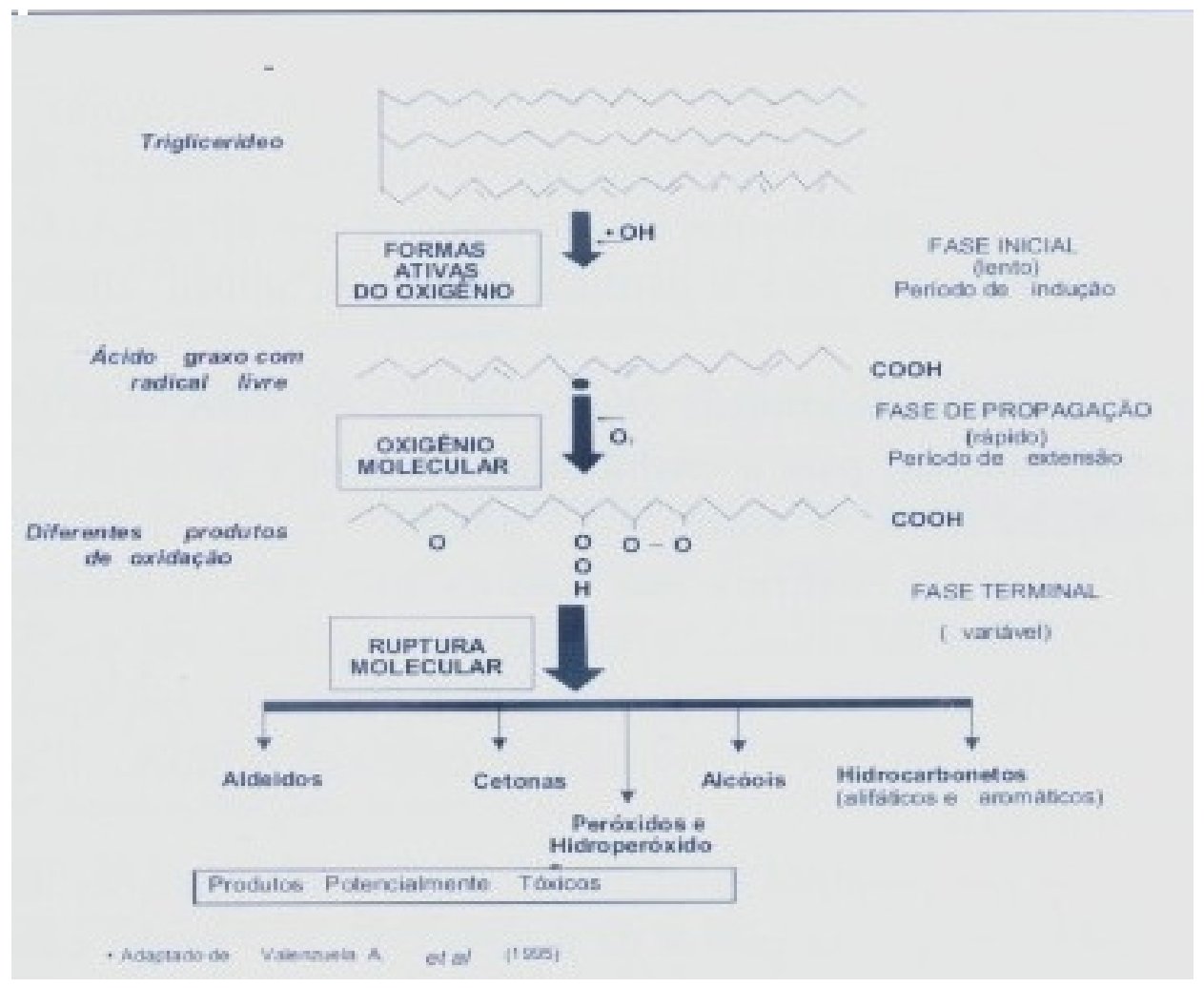

Figura 1 - Etapas da Rancidez Oxidativa 
CONEGLIAN, S.M. et al. Utilização de antioxidantes nas rações. PUBVET, Londrina, V. 5, N. 5, Ed. 152, Art. 1026, 2011.

Das três etapas do processo, a mais importante em termos de controle e prevenção da rancidez oxidativa é a fase inicial, que dependendo de condições específicas pode ser lenta e modificada mediante a adição de antioxidantes.

\section{TOXIDADES DOS PRODUTOS DAS REAÇÕES DE OXIDAÇÃO}

A oxidação lipídica dos alimentos, além de comprometer as características sensoriais como o aroma, sabor, cor, e textura, produzem substâncias de comprovado efeito tóxico.

A ingestão de produtos primários da deteriorização oxidativa de ácidos graxos promove irritação da mucosa intestinal, diarréia, degeneração hepática e até morte das células (CLUTTON, 1997; FERRARI, 1998). Em relação aos produtos secundários, destacam-se o malonaldeido, o 4-hidroxinonenal e a acroleína, que estão relacionados à aterosclerose, ao diabetes, à anemia hemolítica, à inflamação, à mutagênese e ao câncer (BIRD et al., 1982a, BIRD et al., 1982b, BASU \& MARNETT, 1983; HABERLAND et al., 1992; GUTTERIDGE, 1995).

A oxidação lipídica traz prejuízos nutricionais devido à perda parcial de vitaminas lipossolúveis, a co-oxidação da vitamina C, a formação de lipídeos oxidados antagonistas de nutrientes essenciais (tiamina, riboflavina, proteínas, lisina, aminoácidos sulfurados, vitamina B12, pantotenato, etc) e a destruição parcial dos ácidos graxos insaturados essenciais.

Outro problema da oxidação lipídica em alimentos, consiste na propriedade do malonaldeido de reagir com aminas secundárias, formando as nitrosaminas, agentes potencialmente cancerígenos.

No entanto, KAHL e KAPPUS (1993) concluem que as dosagens normalmente utilizadas de BHA e BHT são seguras. 
CONEGLIAN, S.M. et al. Utilização de antioxidantes nas rações. PUBVET, Londrina, V. 5, N. 5, Ed. 152, Art. 1026, 2011.

\section{MÉTODOS DE QUANTIFICAÇÃO DA OXIDAÇÃO EM ALIMENTOS}

Um problema freqüente encontrado é como avaliar o estado de conservação e a eficiência do antioxidante utilizado. O critério mais fácil é o odor, de fácil detecção quando o alimento contém alto conteúdo de lipídeos, mas é um critério subjetivo, não quantitativo e não definitivo. Por este motivo é que a maneira mais correta é a avaliação química da rancidez oxidativa.

O processo de oxidação gera determinados compostos em diferentes momentos. A avaliação destes produtos é utilizada para quantificar o processo oxidativo. A formação dos compostos finais durante a oxidação é mostrada na Figura 2.

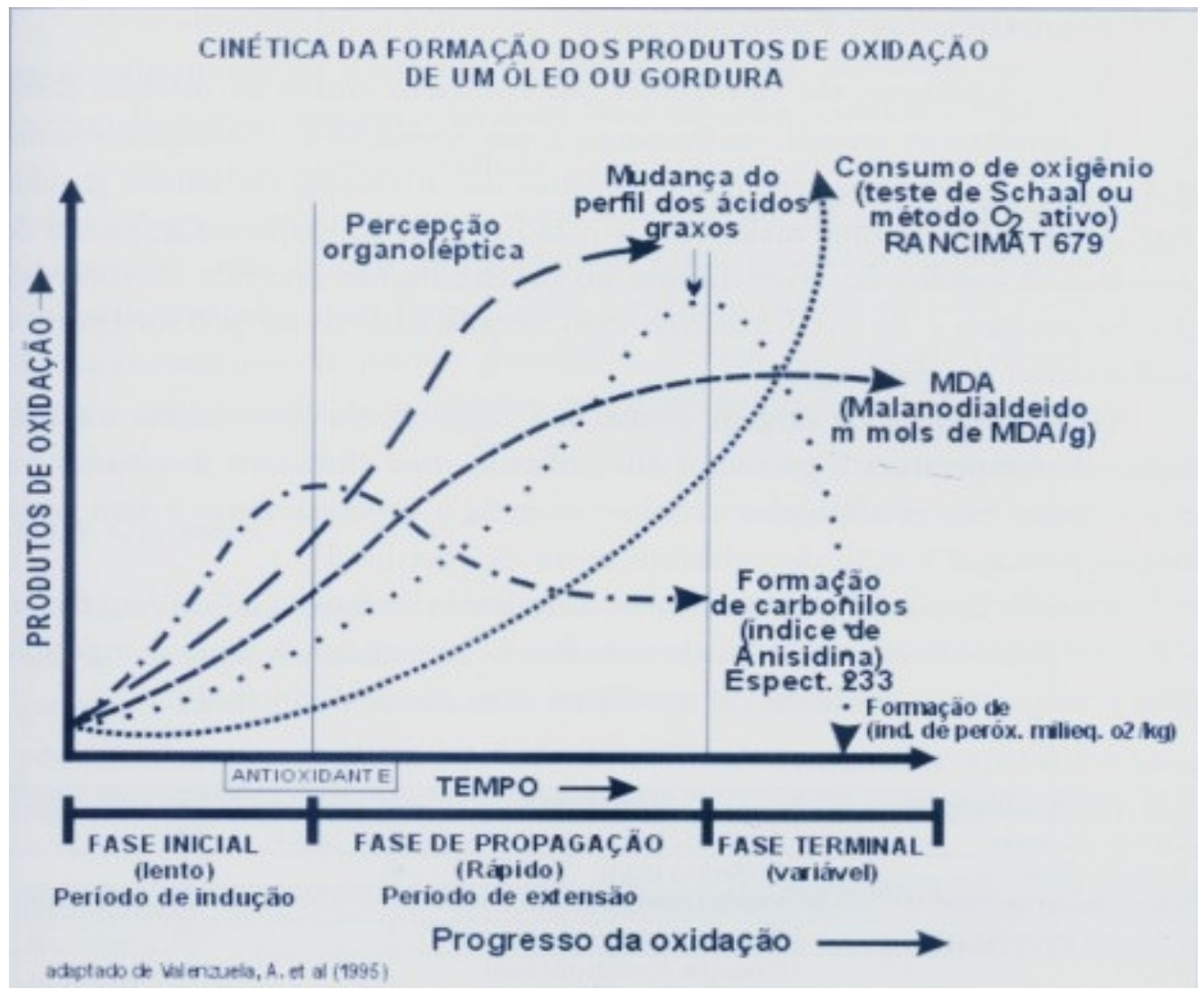

Figura 2 - Cinética da formação dos produtos de oxidação de um óleo ou uma gordura. 
CONEGLIAN, S.M. et al. Utilização de antioxidantes nas rações. PUBVET, Londrina, V. 5, N. 5, Ed. 152, Art. 1026, 2011.

Entre os métodos mais utilizados, podemos citar (WOOLFORD, sem data):

- Índice de peróxidos - método empírico em que se quantifica o iodo liberado do iodeto de potássio pela ação dos peróxidos. Quanto maior o valor deste iodo (expresso em $\mathrm{meq} / \mathrm{kg}$ de produto testado), maior a quantia de peróxidos, portanto maior a oxidação. Contudo, dependendo do momento do processo oxidativo, o valor peróxido poderá ser baixo, e a oxidação estar bem adiantada, como mostrado na Figura 2. Valores entre 1 e 10 são aceitáveis.

- Valor TBA - método também empírico consiste na quantificação do malonaldeido formado pela reação do ácido tiobarbitúrico com aldeídos gerados na fase de terminação da auto-oxidação. O resultado é expresso como $\mathrm{mg}$ de malonaldeido/kg de material testado, ou valor TBA. Valores acima de 1,8 indicam deterioração. (RHEE et al., 1984; WOOLFORD, sem data).

- Índice iodo - O iodo reage com as duplas ligações dos ácidos graxos. Uma diminuição dos valores iodo de uma amostra indicariam uma perda das insaturações, demonstrando desenvolvimento de oxidação.

- Método do oxigênio ativo (MOA, ou teste de Swift) - É um método dinâmico, que informa a resistência de um alimento à oxidação. Uma amostra é submetida a $98^{\circ} \mathrm{C}$ e sob injeção de ar. São feitas avaliações seqüenciais do índice de peróxido, determinando-se o período de iniciação (WOOLFORD, sem data). 
CONEGLIAN, S.M. et al. Utilização de antioxidantes nas rações. PUBVET, Londrina, V. 5, N. 5, Ed. 152, Art. 1026, 2011.

\section{CRITÉRIOS PARA UTILIZAÇÃO DOS ANTIOXIDANTES}

Para os antioxidantes poderem ser utilizados na alimentação animal, devem seguir as seguintes qualificações:

- Devem ser eficaz na conservação de gordura de origem animal e vegetal, vitaminas e outros alimentos que estão sujeito à destruição oxidativa;

- Não deve ser tóxico ao homem e aos animais domésticos;

- Deve ser eficaz em baixas concentraçãos;

- Deve ser economicamente viável.

\section{ANTIOXIDANTES SINTÉTICOS}

Os principais antioxidantes sintéticos utilizados habitualmente nos alimentos são os fenóis com várias substituições no anel (Figura 3).

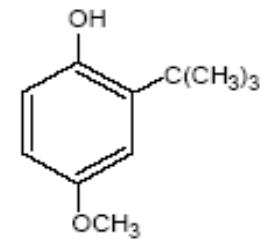<smiles>Cc1cc(C(C)(C)C)c(O)c(C(C)(C)C)c1</smiles><smiles>CC(C)(C)c1cc(O)ccc1O</smiles>

Butil hidroxianisol (BHA)

Butil hidroxitolueno $(\mathrm{BHT})$

Ter butilhidroquinona (TBHQ)<smiles>O=C(O)c1cc(O)c(O)c(O)c1</smiles>

Galato de propila (PG)<smiles>CC(Cc1ccc(O)c(O)c1)C(C)Cc1ccc(O)c(O)c1</smiles>

Ácido nordihidroguaiarético (NDGA)

Fonte: Oliveira, 2003

Figura 3. Estrutura química dos principais antioxidantes sintéticos. 
CONEGLIAN, S.M. et al. Utilização de antioxidantes nas rações. PUBVET, Londrina, V. 5, N. 5, Ed. 152, Art. 1026, 2011.

A eficácia de um antioxidante está relacionada com muitos fatores, como a energia de ativação, as constantes de velocidade, o potencial de óxido-redução, a facilidade com a qual se pode destruir ou perder o antioxidante e a sua solubilidade. Os antioxidantes fenólicos são excelentes doadores de elétrons ou de hidrogênio e, além disso, seus radicais intermediários são relativamente estáveis devido à deslocação por ressonância e à falta de posições moleculares apropriadas para serem atacados pelo oxigênio molecular.

O fenômeno de sinergismo se produz quando uma mistura de antioxidantes têm uma atividade mais acentuada do que a atividade dos antioxidantes individuais. São conhecidos dois tipos de sinergismo, um deles que implica a ação de aceptores de radicais livres misturados e um outro que combina a ação de um aceptor de radical livre e um quelante de metais.

Estudos revelam que os antioxidantes BHA e BHT poderiam apresentar certa toxicidade e eficiência mais baixa que alguns antioxidantes naturais, junto com uma maior consciência dos consumidores com atenção na segurança dos aditivos nos alimentos, cria a necessidade de identificar fontes naturais alternativas de antioxidantes para alimentos (WANASUNDARA e SHAHIDI, 1997).

Na Tabela 1 são mostradas as características gerais de dois antioxidantes sintéticos, o BHT e a etoxiquim.

O BHT parece ser mais instável a elevações de temperatura que os demais antioxidantes sintéticos. Em produtos (alimentos) que sofrerão tratamentos térmicos (frituras, por exemplo), o BHA é mais indicado (NATIONAL TOXICOLOGY PROGRAM, 2000).

Os antioxidantes sintéticos têm se mostrado muito eficientes, e assim são amplamente utilizados pela indústria de alimentos/rações. 
CONEGLIAN, S.M. et al. Utilização de antioxidantes nas rações. PUBVET, Londrina, V. 5, N. 5, Ed. 152, Art. 1026, 2011.

TABELA 1 - Características do butil hidroxitolueno e etoxiquinina

\begin{tabular}{|l|l|l|}
\hline Característica & BHT & Etoxiquim \\
\hline apresentação & pó & pó, líquido, emulsão \\
\hline coloração & $\begin{array}{l}\text { branca, } \\
\text { amarelar-se }\end{array}$ & amarelo à marrom \\
\hline solúvel em água & não & não \\
\hline$T^{\circ}$ volatilização & $70^{\circ} \mathrm{C}$ & - \\
\hline odor & suave & característico \\
\hline higroscopia & muito baixa & - \\
\hline dosagem indicada & 200 ppm & 150 ppm \\
\hline
\end{tabular}

(-) característica não informada

Fonte: (FARMALAND, 1998a; b)

LIN et al. (1991) observaram melhora na qualidade da carne (resistência à oxidação) de frangos alimentados com rações que continham BHT ou BHA.

PARKE e LEWIS (1992) relatam em sua revisão a boa capacidade dos antioxidantes sintéticos em preservar as características sensoriais dos alimentos, bem como garantir proteção contra os metabólitos de oxigênio reativo,substâncias de grande risco para a saúde.

O BHT parece ser menos estável entre os sintéticos. O BHA mostrou-se mais estável que o TBHQ e BHT (maior retenção do antioxidante após 2 meses de processamento fermentativo de peixes), e o TBHQ proporcionou a menor oxidação (OSHIMA et a. 1998).

FARKAS et al. (1997) observaram efetividade de 200 ppm de TBHQ em óleos altamente insaturados.

O BHT mostrou-se eficiente para diminuir os efeitos deletérios da aflotoxina sobre o desempenho de frangos de corte, em doses 3 vezes (EHRICH et. al., 1986) e várias vezes (LARSEN et al., 1985) acima da recomendada. No primeiro 
CONEGLIAN, S.M. et al. Utilização de antioxidantes nas rações. PUBVET, Londrina, V. 5, N. 5, Ed. 152, Art. 1026, 2011.

trabalho foi também testada a etoxiquinina, que não reduziu os prejuízos causados pela aflotoxina. EHRICH et. al. (1988) observaram que junto com a redução dos efeitos negativos da aflotoxina sobre o sistema imune de frangos com o uso do BHT, houve estímulo das enzimas hepáticas responsáveis pelo metabolismo da micotoxina.

O TBHQ foi introduzido na década de 70 e aprovado como antioxidante alimentício em 1972. Ele é um pó cristalino, branco e brilhoso, de odor muito leve e ponto de ebulição mínimo na faixa de $125-126^{\circ} \mathrm{C}$.

Em relação à solubilidade, SHERWIN \& THOMPSON, 1967, em trabalhos com banha, óleos de soja, algodão e açafrão, e gorduras de aves, concluíram que - BHA tem uma solubilidade similar ao TBHQ, enquanto que o BHT e o PG encontraram dificuldades de solubilização.

Com relação aos óleos vegetais insaturados, SHERWIN \& THOMPSON, 1967, verificaram que o poder antioxidante do TBHQ, é superior ao BHA, BHT e ao PG.

Em estudo desenvolvido com a finalidade monitorar a qualidade da farinha de carne e ossos (FCO), durante o armazenamento prolongado (10 semanas), e avaliar os efeitos da adição do BHT $(500 \mathrm{mg} / \mathrm{kg})$ a esta farinha, RACANICCI (2000), observou que o antioxidante BHT diminuiu significativamente o índice de peróxido, conforme mostrado na Tabela 1 e Figura 4. 
CONEGLIAN, S.M. et al. Utilização de antioxidantes nas rações. PUBVET, Londrina, V. 5, N. 5, Ed. 152, Art. 1026, 2011.

Tabela 1 - Índice de peróxidos (IP, meq/kg) das amostras de FCO coletadas

\begin{tabular}{lc|c|c|c|c|c|c|c|c|c|c} 
Trat. & \multicolumn{10}{c|}{ Amostragens } \\
\hline & $\mathbf{3 1 / 0 3}$ & $\mathbf{0 6 / 0 4}$ & $13 / 04$ & $\mathbf{2 0 / 0 4}$ & $\mathbf{2 7 / 0 4}$ & $\mathbf{0 4 / 0 5}$ & $11 / 05$ & $18 / 05$ & $25 / 05$ & $01 / 06$ & $08 / 06$ \\
\hline Contr. & 0,00 & 0,00 & 34,29 & 28,12 & 60,70 & 38,77 & 43,20 & 61,12 & 79,72 & 76,29 & 69,23 \\
\hline BHT/0 & 0,00 & 0,00 & 0,00 & 0,00 & 0,00 & 0,00 & 0,00 & 0,00 & 0,00 & 0,00 & 0,00 \\
\hline BHT/7 & 0,00 & 0,00 & 0,00 & 0,00 & 0,00 & 0,00 & 0,00 & 0,00 & 0,00 & 0,00 & 0,00 \\
\hline BHT/14 & 0,00 & 0,00 & 34,29 & 5,60 & 10,80 & 11,55 & 17,97 & 13,09 & 13,71 & 8,45 & 9,59 \\
\hline BHT/21 & 0,00 & 0,00 & 34,29 & 28,12 & 27,61 & 31,16 & 29,50 & 39,78 & 26,00 & 29,50 & 47,60 \\
\hline BHT/28 & 0,00 & 0,00 & 34,29 & 28,12 & 60,70 & 41,41 & 16,15 & 45,13 & 52,73 & 45,71 & 45,72 \\
\hline
\end{tabular}

Fonte: Racanicci, 200

Fonte: Racanicci, 2000

A adição de $500 \mathrm{mg} / \mathrm{kg}$ de BHT na FCO foi efetiva na prevenção da rancidez oxidativa, quando feita no momento do recebimento da FCO ou depois de 7 dias. Nas condições deste estudo, a FCO sem adição de antioxidante permaneceu com IP abaixo do padrão máximo permitido $(10 \mathrm{meq} / \mathrm{kg}$ ) por pouco mais de uma semana. Após o início do processo oxidativo na FCO, a adição de BHT pode ou não controlar o seu avanço, dependendo do grau de oxidação da farinha no momento da adição. 
CONEGLIAN, S.M. et al. Utilização de antioxidantes nas rações. PUBVET, Londrina, V. 5, N. 5, Ed. 152, Art. 1026, 2011.

a)

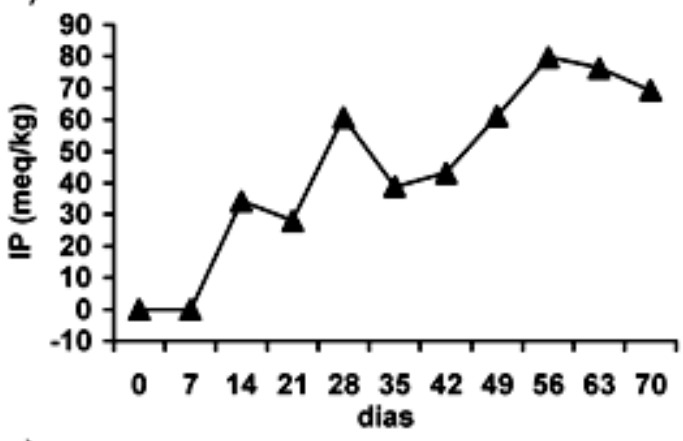

c)

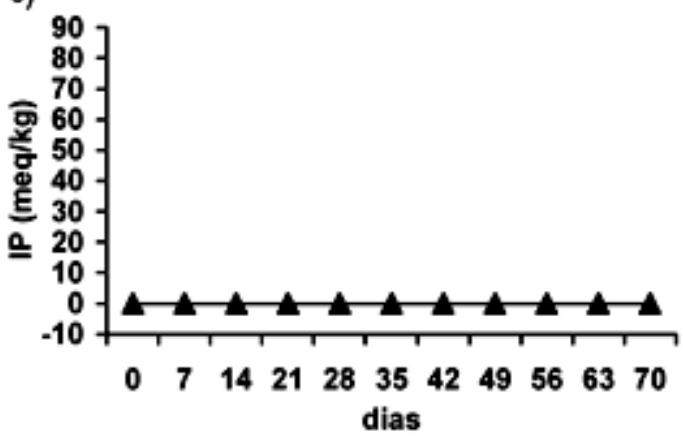

e)

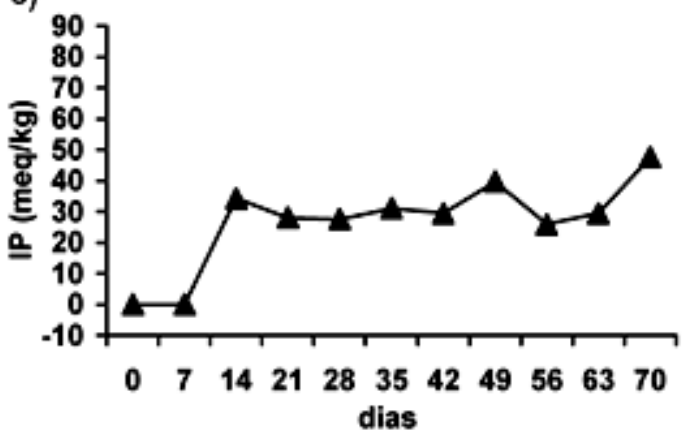

b)

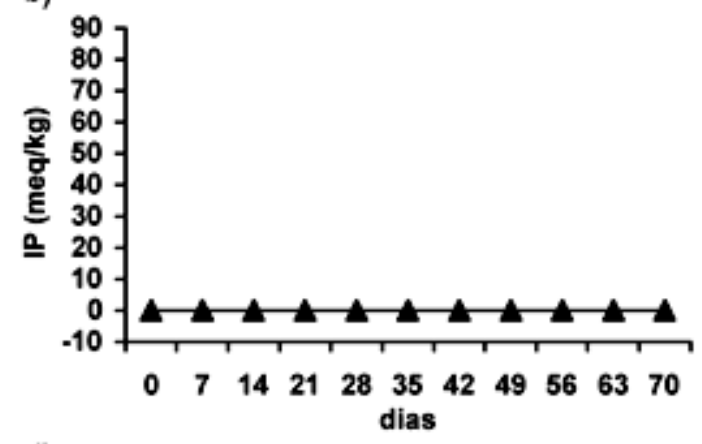

d)

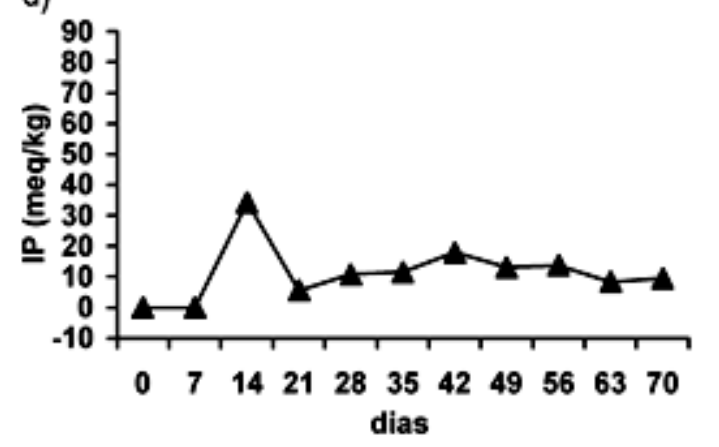

f)

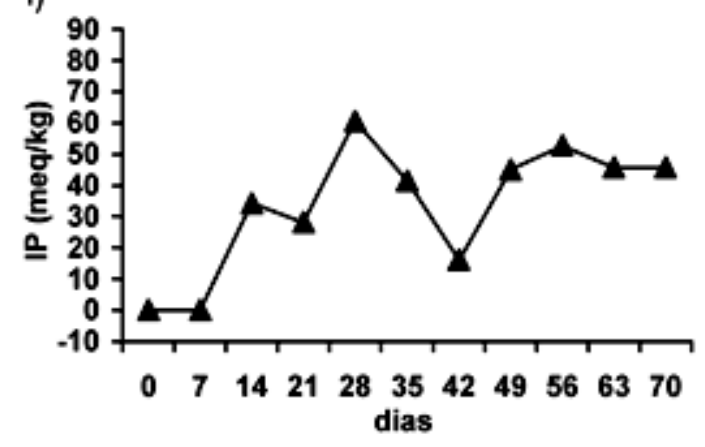

Fonte: Racanicci, 2000

Figura 4 - Índice de peróxidos (IP, meq/kg) das amostras de FCO coletadas semanalmente por tratamento.a)controle;

b) $\mathrm{BHT} / 0$;

c) $\mathrm{BHT} / 7$;

d) $\mathrm{BHT} / 14$; e)BHT/21; f) BHT/28.

Segundo OLIVEIRA (2003), o antioxidante TBHQ, foi eficiente quando adicionado ao óleo de milho e óleo de canola, diminuindo o índice de peróxido e aumentando o índice de iodo (TABELA 2,3, 4 e 5). 
CONEGLIAN, S.M. et al. Utilização de antioxidantes nas rações. PUBVET, Londrina, V. 5, N. 5, Ed. 152, Art. 1026, 2011.

Tabela 2 - Índice de peróxido (meq $\mathrm{O}_{2} / \mathrm{kg}$ óleo) do óleo de milho adicionado de diferentes concentrações de TBHQ.

\begin{tabular}{|l|c|c|c|c|c|c|c|}
\hline \multicolumn{7}{|c|}{ Tempo (meses) } \\
\hline Tratamentos & 0 & 1 & 2 & 3 & 4 & 5 & 6 \\
\hline Controle & $0,95^{\mathrm{aE}}$ & $1,41^{\mathrm{aE}}$ & $2,90^{\mathrm{aD}}$ & $3,40^{\mathrm{aD}}$ & $4,11^{\mathrm{aC}}$ & $6,78^{\mathrm{aB}}$ & $8,31^{\mathrm{aA}}$ \\
\hline $115 \mathrm{mg} / \mathrm{Kg}$ & $0,95^{\mathrm{aD}}$ & $1,20^{\mathrm{aD}}$ & $2,34^{\mathrm{bC}}$ & $2,73^{\mathrm{bC}}$ & $3,93^{\mathrm{aB}}$ & $3,93^{\mathrm{bB}}$ & $4,88^{\mathrm{bA}}$ \\
\hline $200 \mathrm{mg} / \mathrm{kg}$ & $0,95^{\mathrm{aD}}$ & $1,16^{\mathrm{aD}}$ & $2,70^{\mathrm{bC}}$ & $2,74^{\mathrm{bC}}$ & $3,67^{\mathrm{aB}}$ & $3,63^{\mathrm{bB}}$ & $4,77^{\mathrm{bA}}$ \\
\hline
\end{tabular}

Fonte: Oliveira, 2003

Tabela 3 - Índice de iodo (mg/ $100 \mathrm{mg}$ óleo) do óleo de milho adicionado de diferentes concentrações de TBHQ.

\begin{tabular}{|l|c|c|c|}
\hline \multicolumn{4}{|c|}{ Tempo (meses) } \\
\hline \multicolumn{1}{|c|}{ Tratamentos } & 0 & 3 & 6 \\
\hline Controle & $110,31^{\mathrm{aA}}$ & $107,92^{\mathrm{aB}}$ & $103,80^{\mathrm{bC}}$ \\
\hline $115 \mathrm{mg} / \mathrm{Kg}$ & $110,31^{\mathrm{aA}}$ & $108,34^{\mathrm{aB}}$ & $105,11^{\mathrm{aC}}$ \\
\hline $200 \mathrm{mg} / \mathrm{kg}$ & $110,31^{\mathrm{aA}}$ & $107,65^{\mathrm{aB}}$ & $103,92^{\mathrm{bC}}$ \\
\hline
\end{tabular}

Fonte: Oliveira, 2003

Tabela 4- Índice de peróxido ( $m e q \mathrm{O}_{2} / \mathrm{kg}$ óleo) do óleo de canola adicionado de diferentes concentrações de TBHQ.

\begin{tabular}{|l|c|c|c|c|c|c|c|}
\hline \multicolumn{7}{|c|}{ Tempo (meses) } \\
\hline Tratamentos & 0 & 1 & 2 & 3 & 4 & 5 & 6 \\
\hline Controle & $0,93^{\mathrm{aC}}$ & $2,51^{\mathrm{aC}}$ & $6,52^{\mathrm{aD}}$ & $7,16^{\mathrm{aAD}}$ & $7,51^{\mathrm{aA}}$ & $8,20^{\mathrm{aA}}$ & $8,06^{\mathrm{aAB}}$ \\
\hline $108 \mathrm{mg} / \mathrm{Kg}$ & $0,93^{\mathrm{aE}}$ & $2,26^{\mathrm{aDE}}$ & $3,53^{\mathrm{bCD}}$ & $4,41^{\mathrm{bBC}}$ & $4,79^{\mathrm{bCBC}}$ & $6,12^{\mathrm{bAB}}$ & $7,18^{\mathrm{aA}}$ \\
\hline $200 \mathrm{mg} / \mathrm{kg}$ & $0,93^{\mathrm{aE}}$ & $2,12^{\mathrm{aDE}}$ & $3,01^{\mathrm{bCD}}$ & $3,35^{\mathrm{bCD}}$ & $4,34^{\mathrm{CBC}}$ & $5,75^{\mathrm{bAB}}$ & $7,02^{\mathrm{aA}}$ \\
\hline
\end{tabular}

Fonte: Oliveira, 2003 
CONEGLIAN, S.M. et al. Utilização de antioxidantes nas rações. PUBVET, Londrina, V. 5, N. 5, Ed. 152, Art. 1026, 2011.

Tabela 5- Índice de peróxido ( $m e q \mathrm{O}_{2} / \mathrm{kg}$ óleo) do óleo de canola adicionado de diferentes concentrações de TBHQ.

\begin{tabular}{|l|c|c|c|}
\hline \multicolumn{4}{|c|}{ Tempo (meses) } \\
\hline \multicolumn{1}{|c|}{ Tratamentos } & 0 & 3 & 6 \\
\hline Controle & $119,35^{\mathrm{aA}}$ & $115,08^{\mathrm{bB}}$ & $111,24^{\mathrm{bC}}$ \\
\hline $108 \mathrm{mg} / \mathrm{Kg}$ & $119,35^{\mathrm{aA}}$ & $115,43^{\mathrm{aB}}$ & $111,75^{\mathrm{aC}}$ \\
\hline $200 \mathrm{mg} / \mathrm{kg}$ & $119,35^{\mathrm{aA}}$ & $115,24^{\mathrm{aB}}$ & $111,44^{\mathrm{bC}}$ \\
\hline
\end{tabular}

Fonte: Oliveira, 2003

\section{ANTIOXIDANTES NATURAIS}

Devido às suspeitas de efeitos colaterais provocados pelos antioxidantes sintéticos, tem-se buscado antioxidantes alternativos (naturais) principalmente aqueles presentes em plantas (ADEGOKE, 1998).

A proteção dos lipídeos frente à degradação autoxidativa é garantida pelos antioxidantes. O interesse na pesquisa por novos antioxidantes naturais tem aumentado nos últimos anos, levando às indústrias de alimentos, de cosméticos e farmacêuticas a ter maior atenção em novas fontes de antioxidantes naturais. Os compostos antioxidantes naturais tem sido isolados de diferentes partes de plantas tais como sementes, frutas, folhas e raízes.

Bem como, muitos estudos tem sido realizados na determinação da sua ação antioxidante (DABROWSKI e SOSULSKI, 1984, CHEVOLLEAU, et al., 1992, NAKATANI, 1992).

Nos alimentos, os antioxidantes naturais podem se originar de um ou mais compostos do próprio alimento (via endógena), de substâncias formadas de reações durante o processamento ou como aditivos isolados de fontes naturais (PRATT, 1992). 
CONEGLIAN, S.M. et al. Utilização de antioxidantes nas rações. PUBVET, Londrina, V. 5, N. 5, Ed. 152, Art. 1026, 2011.

Os antioxidantes naturais podem funcionar como agentes redutores, como inibidores de radicais livres, como quelantes ou sequestrantes do oxigênio e como desativadores de metais pró-oxidantes (KÄHKÖNEN, et. al., 1999; RICE-EVANS et al., 1995).

Sendo uma das características dos antioxidantes, retardar o desenvolvimento de sabores e odores desagradáveis ocasionado pela oxidação de ácidos graxos insaturados, usualmente presentes como triacilgliceróis e/ou lipídeos polares, hoje em dia há uma tendência geral, no processamento de alimentos, de substituir os antioxidantes sintéticos pelos inibidores da oxidação natural ou pelo uso preferencial de ingredientes que naturalmente possuem atividade antioxidante (TSALIKI, et.al.,1999).

Entre os antioxidantes naturais, os tocoferóis lipossolúveis têm sido estudados extensamente, mas, o interesse na pesquisa por novos antioxidantes naturais tem aumentado nos últimos anos. O reino vegetal é rico em compostos fenólicos, os quais são encontrados em especiarias e folhas de plantas aromáticas de regiões quentes e secas (ECONOMOU, et. al., 1991).

Também, extratos crus de frutas, ervas, vegetais, cereais e outros materiais ricos em fenólicos são de interesse na indústria de alimentos, pois estes retardam a degradação oxidativa de lipídeos, melhorando deste modo a qualidade e o valor nutricional dos alimentos. Por conseguinte, existe um interesse crescente no isolamento, identificação e na utilização dos componentes antioxidantes de fontes naturais. YANISHLIEVA e MARINOVA, (1995), verificaram que ácidos fenólicos tais como o ferúlico, sinápico e caféico estão envolvidos em vários estágios das reações de iniciação e propagação durante a oxidação de triacilgliceróis puros e metil ésteres do óleo de girassol.

Já, compostos fenólicos, incluindo flavonóides, ácido tânico e ácido elágico são 
CONEGLIAN, S.M. et al. Utilização de antioxidantes nas rações. PUBVET, Londrina, V. 5, N. 5, Ed. 152, Art. 1026, 2011.

encontrados em plantas e apresentam elevada atividade antioxidante em diversos sistemas biológicos (RAMANATHAN e DAS, 1992). Além disso, os compostos fenólicos de plantas podem reter ou retardar o início da oxidação lipídica, influindo tanto na decomposição de hidroperóxidos nos alimentos, como também, em tecidos animais (WETTASINGHE e SHAHIDI, 1999). Muitos autores relataram que os extratos de várias sementes oleaginosas possuem propriedade antioxidante, a qual, em alguns casos exercem melhor efeito antioxidante que o observado pelos antioxidantes sintéticos nas mesmas concentrações (AMAROWICZ, et al., 1993; OOMAH, et al., 1995).

Para WANASUNDARA et al., (1997), muitos são os componentes naturalmente presentes nos alimentos que apresentam atividade antioxidante, incluem flavonóides, precursores de lignanos, ácidos fenólicos, terpenos, tocoferóis, fosfolípides, etc. (Figura 5).

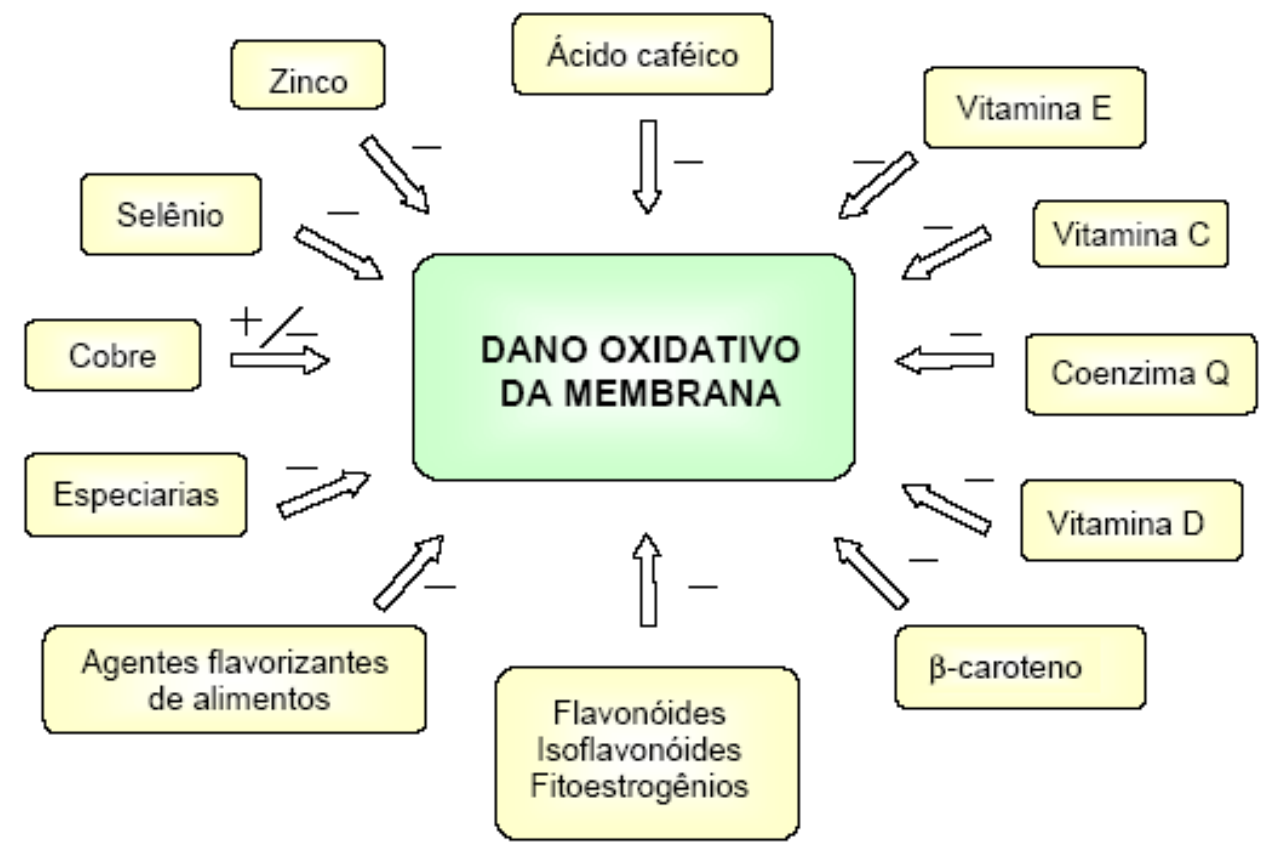

Fonte: WISEMAN (1996)

Figura 5. Proteção contra o dano oxidativo da membrana, mediada pela dieta. 
CONEGLIAN, S.M. et al. Utilização de antioxidantes nas rações. PUBVET, Londrina, V. 5, N. 5, Ed. 152, Art. 1026, 2011.

\section{1 - Tocoferóis:}

Os isômeros de tocoferol (vitamina E) estão presentes nos vegetais, desempenhando função antioxidante para a manutenção dos tecidos, assim como desempenham antioxidante também nos tecidos animais. Suas estruturas moleculares são mostradas na Figura 6.



Fontes: Machlin, 1984

Figura 6 - Fórmula química do tocoferol

Tocoferóis agem principalmente da propagação e terminação do processo oxidativo, estabilizando radicais livres formados pelos ácidos graxos. Seus isômeros diferem entre si quanto a sua potência: o isômero delta é o mais potente, seguido pelo gama, beta e alfa isômeros (VALENZUELA, 1995).

Há duas décadas, DIPLOCK (1984) propôs que o tocoferol ficaria localizado dentro da membrana celular e que todo sistema está estabilizado por forças físico-químicas, envolvendo interações entre o tocoferol e os fosfolipídeos polinsaturados das membranas. Posicionado desta forma, o tocoferol protegeria os ácidos graxos polinsaturados da peroxidação pelos radicais livres produzidos pelas enzimas, ligadas de maneira adjacente às membranas.

Monahan et al.,(1990 a, b) avaliaram o tempo de estocagem da carne de suínos alimentados com dietas contendo vitamina $\mathrm{E}$, e concluíram que a carne 
CONEGLIAN, S.M. et al. Utilização de antioxidantes nas rações. PUBVET, Londrina, V. 5, N. 5, Ed. 152, Art. 1026, 2011.

destes animais permaneciam por mais tempo sem sofrer o processo de oxidação, estando esta carne crua ou cozida (Figuras 6 e 7).

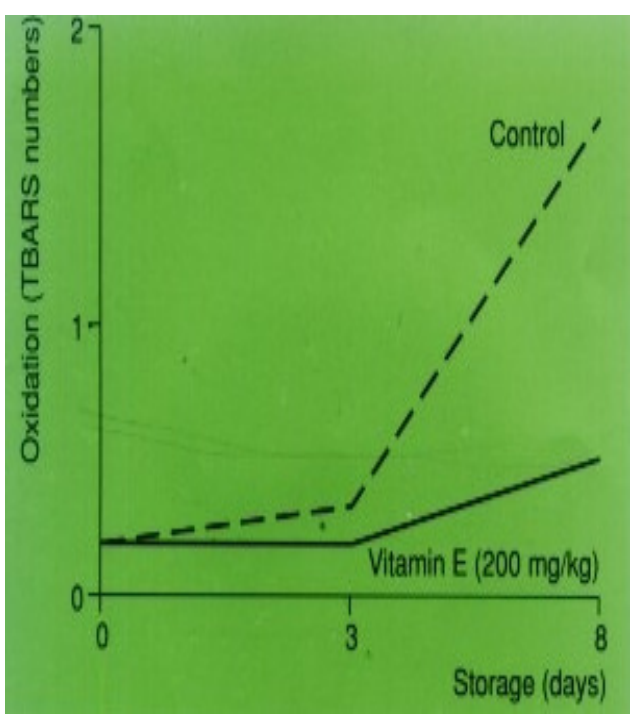

Fonte:Monahan, 1990

Figura 6 - Oxidação da carne crua suína em relação ao tempo de estocagem.

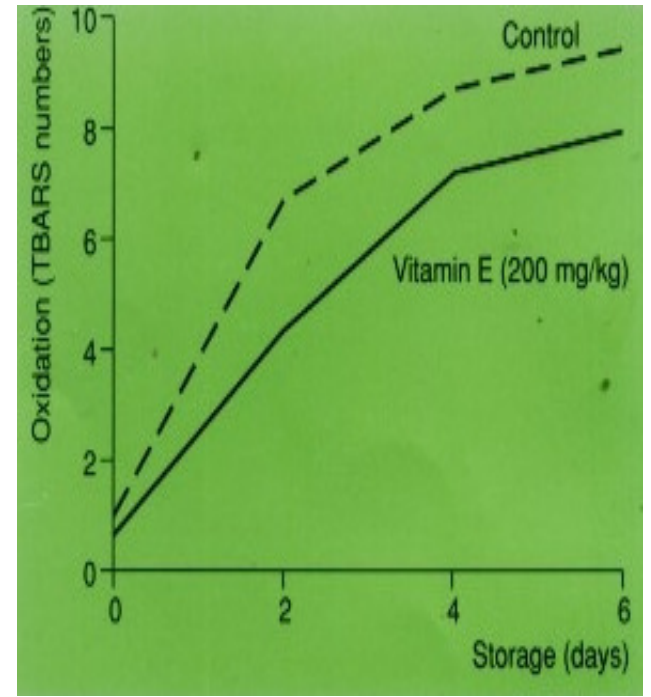

Fonte: Monahan, 1990

Figura 7 - Oxidação da carne cozida suína em relação ao tempo de estocagem.

Em recentes estudos feitos na Universidade de Wisconsin, Madison, US, pesquisadores analisaram o efeito da suplementação de vitamina $E$ em bovinos, e observaram diferentes resultados no tempo de armazenamento da carne destes animais (Figura 8). 
CONEGLIAN, S.M. et al. Utilização de antioxidantes nas rações. PUBVET, Londrina, V. 5, N. 5, Ed. 152, Art. 1026, 2011.
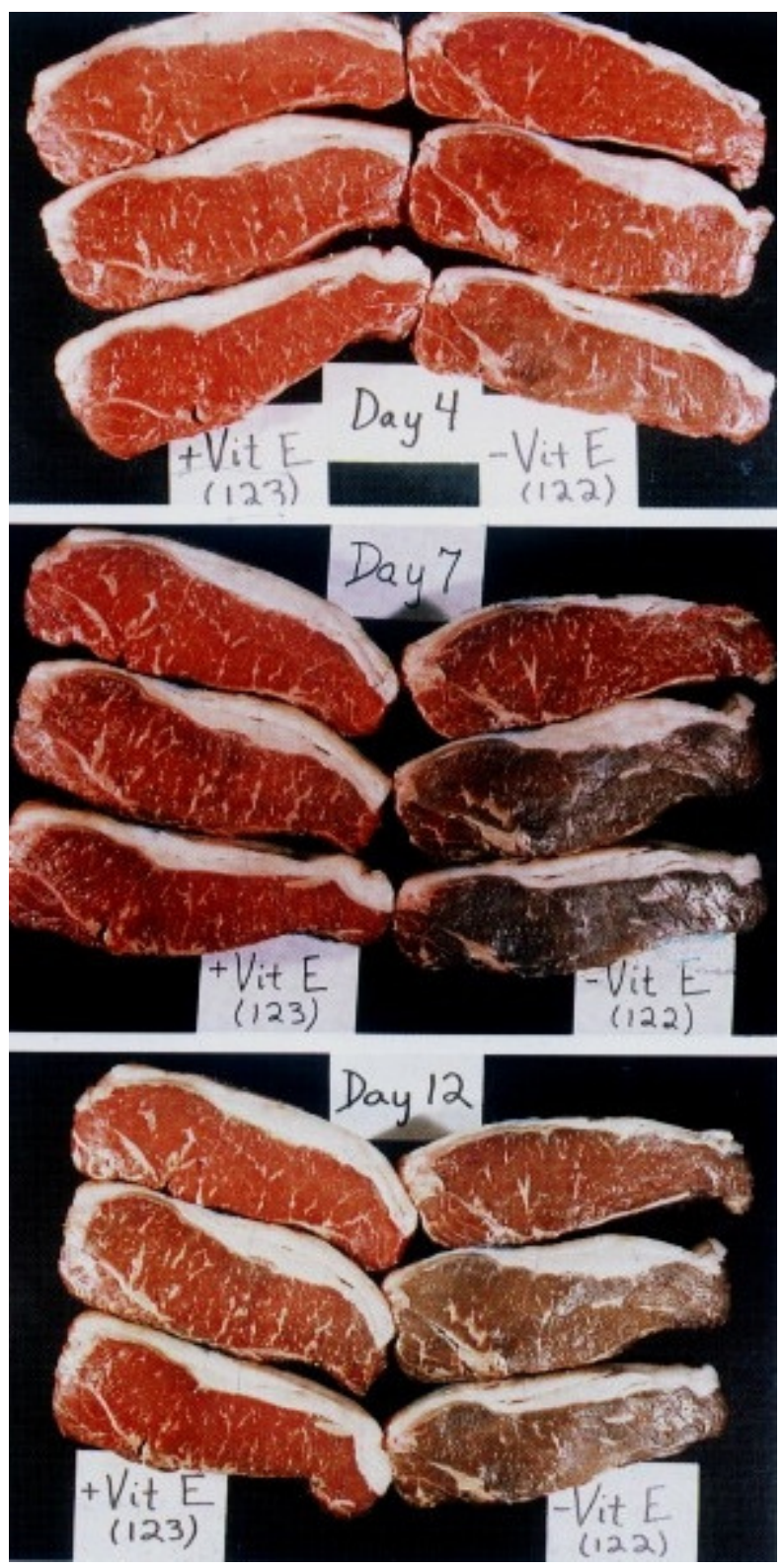

Fonte: University of Wisconsin, sem data

Figura 8 - Influência da suplementação de Vitamina E na coloração de carne bovina.

A carne dos animais que foram suplementados com vitamina $E$ permaneceram saudáveis até 12 dias após o abate, e a carne dos animais que 
CONEGLIAN, S.M. et al. Utilização de antioxidantes nas rações. PUBVET, Londrina, V. 5, N. 5, Ed. 152, Art. 1026, 2011.

não receberam esta suplementação tiveram um tempo de validade de apenas 4 dias.

ALLEN \& HAMILTON, 1989, estimaram que a perda do valor nutritivo da carne causado pela deteriorização, foi de 5,4\%.

\section{2 - Flavonóides:}

Compreendem um grande grupo de substâncias derivadas do flavone (2fenilbenzopirone), que apresenta dois anéis benzenos ligados por uma estrutura de 3 carbonos, condensada a um dos anéis (BROWN et al., 1998), como mostrado na Figura 9.

FIGURA 9 - Alguns flavonóides antioxidantes
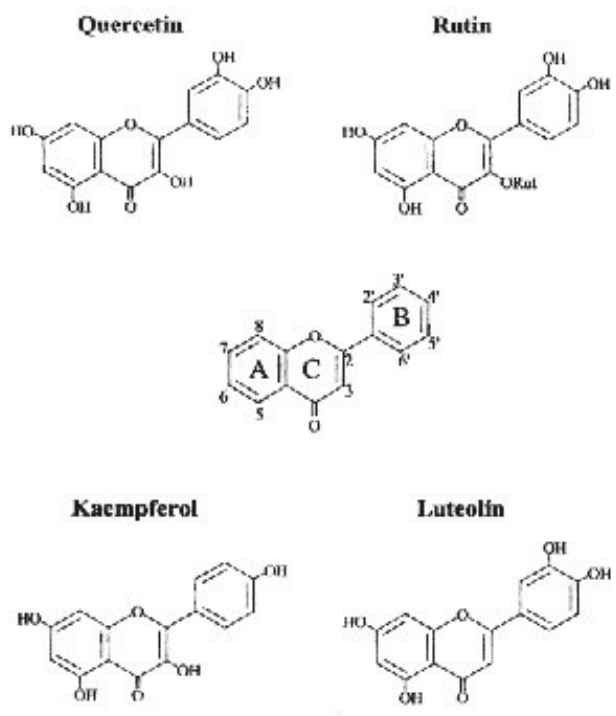

Fonte: Brown et al., 1998 
CONEGLIAN, S.M. et al. Utilização de antioxidantes nas rações. PUBVET, Londrina, V. 5, N. 5, Ed. 152, Art. 1026, 2011.

FRAGA et al. 1987 citado por VALENZUELA (1995) citam que a ação dos flavonóides se dá através do seqüestro de formas excitadas de oxigênio da fase inicial do processo oxidativo. Uma vez que os tocoferóis agem em fases posteriores, pode-se notar um efeito sinérgico entre estes compostos.

Os flavonóides são encontrados em diversos produtos, como alho, diversos legumes, vinho, apresentando vários efeitos benéficos à saúde, incluindo propriedades anticarcinogênicas (FORMICA e REGELSON, 1995) e CHEN et al. (1996) observaram que a mirecetina é um efetivo antioxidante.

As catequinas (um grupo de flavonóides) são encontradas em alguns chás (WANASUNDARA e SHAHIDI, 1996; CHEN e CHAN, 1996; VONGADOW et al., 1997). Todos esses autores observaram uma ação antioxidante das catequinas compatíveis com o BHT, tocoferóis e até melhor que o TBHQ.

\section{3 - Vitamina A:}

O beta caroteno (precursor da vitamina A) tem sido testado por seus efeitos antioxidantes. HAILA e HEINONEN (1994) concluem que há um potencial benefício no sinergismo entre beta caroteno e tocoferóis, em sistemas antioxidantes e PASSOTO et al. (1998) observaram eficiência do beta-caroteno e do acetato de retinol (vitamina A) na estabilização de lipídeos, ainda que estes dois antioxidantes tenham apresentado efeito menor que o $\mathrm{BHT}$, como mostrado na Tabela 6. 
CONEGLIAN, S.M. et al. Utilização de antioxidantes nas rações. PUBVET, Londrina, V. 5, N. 5, Ed. 152, Art. 1026, 2011.

TABELA 6 - Efeito do beta-caroteno, acetato de retinol e BHT (100ppm) na formação de peróxidos (meq/kg) e no óleo de soja a $50^{\circ} \mathrm{C}$, confrontados com seus respectivos controles

\begin{tabular}{lllllll}
\hline $\begin{array}{l}\text { Tempo } \\
\text { (h) }\end{array}$ & $\begin{array}{l}\beta- \\
\text { caroteno }\end{array}$ & controle & retinol & controle & BHT & controle \\
\hline 24 & 46.9 & 47.5 & 41.65 & 44.05 & 44.7 & 48.45 \\
48 & 52.6 & 61.3 & 32.05 & 82.9 & 24.25 & 85.8 \\
72 & $131.3^{*}$ & 151.3 & $53.15^{*}$ & 245.95 & $25 *$ & 228.1 \\
\hline
\end{tabular}

Fonte: Passoto et al, 1998

\section{4 - Vitamina C:}

A vitamina $C$ ajuda o organismo a proteger-se contra a ação dos radicais livres, e quando utilizada junto com a vitamina $E$ e a vitamina $A$, possui uma potência ainda mais eficaz, uma vez que regenera a capacidade antioxidante desta última. De acordo com vários pesquisadores, a suplementação com vitaminas $\mathrm{C}$ e $\mathrm{E}$ pode ajudar a proteger a memória e o declínio mental à medida que se envelhece.

Necessita ser periodicamente administrada, pois não se acumula no corpo.

\section{5 - Especiarias:}

O termo especiaria é definido como material seco da planta que normalmente é acrescentado ao alimento para melhorar o "flavor" (MADSEN e BERTELSEN, 1995).

Desde antigamente, especiarias e ervas têm sido usadas não somente para melhorar o sabor e odor em alimentos e estender o tempo de prateleira, mas também pelas suas propriedades antisépticas e medicinais. O efeito de 
CONEGLIAN, S.M. et al. Utilização de antioxidantes nas rações. PUBVET, Londrina, V. 5, N. 5, Ed. 152, Art. 1026, 2011.

preservação das especiarias e ervas sugerem a presença de constituintes antioxidantes e antimicrobianos (NAKATANI, 1997), sendo que, segundo MADSEN e BERTELSEN (1995), a atividade antioxidante das especiarias é devido, principalmente, aos compostos fenólicos.

Um grande número de especiarias e ervas foram estudadas, entre elas alecrim, salvia, cravo, canela, orégano, gengibre, noz-moscada, para determinar a atividade antioxidante e identificar os compostos responsáveis pela atividade mencionada. As propriedades antioxidantes de ervas e especiarias são indicadas como efetivas para retardar o processo de peroxidação lipídica em óleos e alimentos gordurosos e têm ganho o interesse de muitos grupos de pesquisa (MILOS et al., 2000). TSIMIDOU e BOSKOU (1994), concluíram que entre as ervas e especiarias extensamente estudadas, as plantas obtidas da família Labiatae possuem uma atividade antioxidante

significativa. Os autores LAGOURI e BOSKOU, (1996), MILOS et al., (2000), trabalharam com a especiaria orégano (Origanum vulgare L.) para detectar a presença de antioxidantes e a sua atividade. Já, com o alecrim (Rosmarinus officinalis L.), FRANKEL et al., (1996), estudaram a sua propriedade antioxidante e OFFORD et al., (1997), determinaram a atividade antioxidante em sistemas lipídicos e não lipídicos. Os antioxidantes podem ser extraídos com êxito com diferentes solventes orgânicos tais como benzeno, clorofôrmio, éter dietílico e metanol. Os extratos das folhas de alecrim contêm um diterpeno fenólico, o carnosol. Além disso, o rosmanol, outro diterpeno fenólico, que tem uma estrutura que está intimamente relacionada ao carnosol e o rosmaridifenol foram também identificados nas folhas de alecrim (HOULIHAN et al., 1984), (Figura 10). Os ácidos carnósico e rosmárico foram indicados como sendo os constituintes do alecrim de maior atividade antioxidante. Os extratos de antioxidantes comerciais (molecular ou destilado a vácuo) do alecrim estão disponíveis como um pó fino. Dependendo da quantidade de atividade dos antioxidantes, eles são 
CONEGLIAN, S.M. et al. Utilização de antioxidantes nas rações. PUBVET, Londrina, V. 5, N. 5, Ed. 152, Art. 1026, 2011.

recomendados para o uso nas concentrações entre 200 e 1000 ppm do produto processado (SHAHIDI e WANASUNDARA, 1992). As folhas secas do orégano foram sucessivamente extraídas com diclorometano e metanol e seus compostos antioxidantes foram isolados, sendo o principal composto identificado como um glicosídeo fenólico (KIKUZAKI e NAKATANI, 1989), (Figura 11).

Figura 10: Estrutura química dos compostos antioxidantes no alecrim

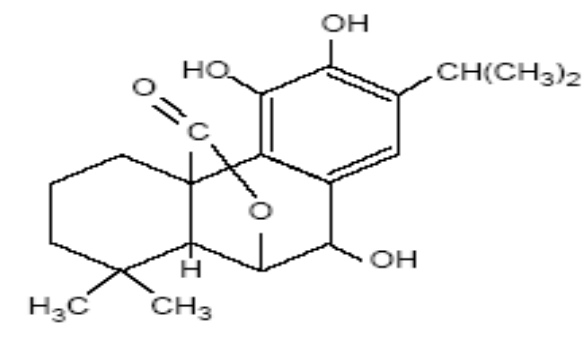

ROSMANOL

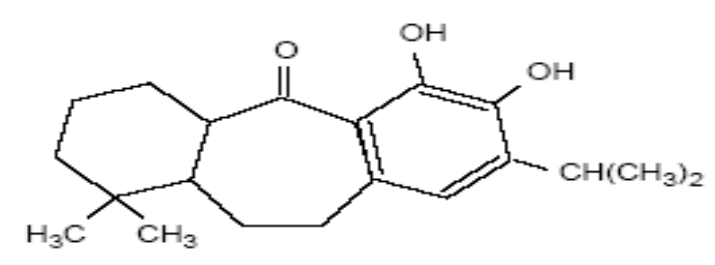

ROSMARIDIFENOL

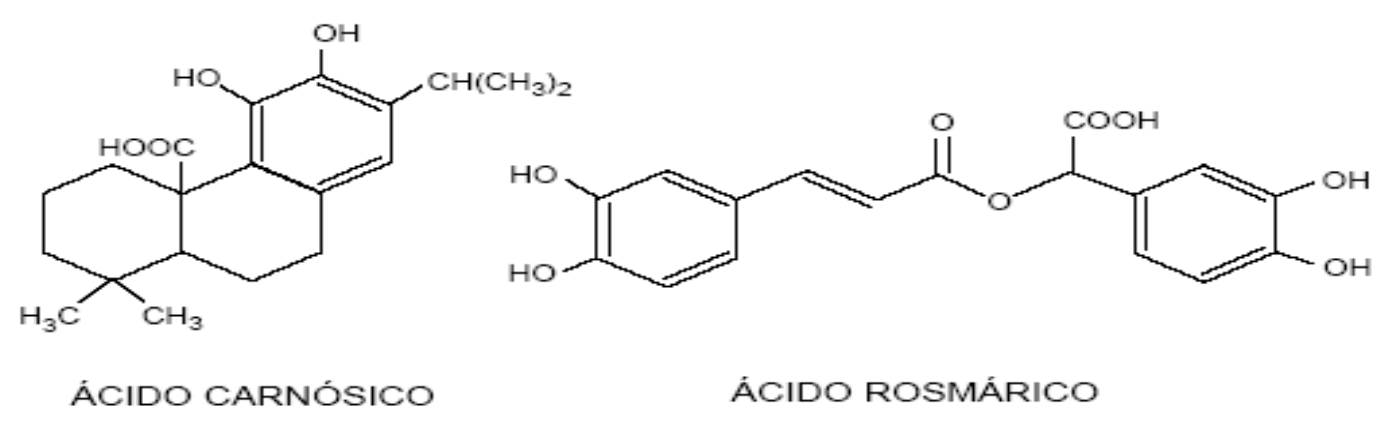

Fonte: Kikuzaki e Nakatani, 1989 
CONEGLIAN, S.M. et al. Utilização de antioxidantes nas rações. PUBVET, Londrina, V. 5, N. 5, Ed. 152, Art. 1026, 2011.

Figura 11: Estrutura química do glicosídeo fenólico antioxidante no orégano<smiles>O=C(OCc1ccc(OC2O[C@@H]3O[C@@H]([C@H](O)CC3CO)[C@H]2O)cc1)c1ccc(O)c(O)c1</smiles>

Fonte: Kikuzaki e Nakatani, 1989

$\mathrm{Na}$ Tabela 7, são apresentadas as atividades antioxidantes de algumas especiarias sob condições de oxidação acelerada.

\begin{tabular}{|l|c|}
\hline Extrato de antioxidante natural & Período inicial à $\mathbf{1 0 0}^{\circ} \mathbf{C}$ (horas) \\
\hline Controle & 5 \\
\hline Nós moscada & 8 \\
\hline Alecrim & 25 \\
\hline Sálvia & 30 \\
\hline Páprica & 10 \\
\hline
\end{tabular}

Fonte: LOLIGER, 1983

\section{CONSIDERAÇÕES FINAIS}

A oxidação dos lipídeos presente nas rações pode levar a perdas no desempenho dos animais e na segurança dos produtos animais para a saúde humana; portanto, deve ser evitada.

O controle da autoxidação é possível com o uso de antioxidantes. 
CONEGLIAN, S.M. et al. Utilização de antioxidantes nas rações. PUBVET, Londrina, V. 5, N. 5, Ed. 152, Art. 1026, 2011.

Antioxidantes sintéticos são muito eficazes, porém não há um consenso quanto a segurança do seu uso.

As recomendações vigentes são de 200 ppm para BHT e BHA e de 150 ppm para etoxiquim, total nas rações, e nestas dosagens seu uso aparentemente é seguro (exceto etoxiquim, que parece ser mais seguro utilizando-se a dosagem de 75 ppm).

Há uma tendência no mercado para a utilização dos antioxidantes naturais, que se mostram promissores, porém sua ação e disponibilidade para uso são, em geral, inferiores aos sintéticos.

Quando se formulam rações utilizando-se pré-misturas, deve-se procurar saber qual o antioxidante presente nos premixes e sua concentração, de forma a se calcular a quantidade que estará presente na ração final e determinar se esta dentro das indicações de uso.

\section{BIBLIOGRAFIA}

ADEGOKE, G. O., KUMAR, M. V., KRISHNA, A. G. G. et al. Antioxidants and lipid oxidation in foods

- a critical appraisal. J. Food Sci. Tech. 35(4):283-298. (abstract), 1998.

AMAROWICZ, R., WANASUNDARA, U., WANASUNDARA, J., SHAHIDI, F. Antioxidant activity of ethanolic extracts of flaxseed in a $\beta$-carotenelinoleate model system. $]$. Food Lipids, Trumbull, v.1, p.111-117, 1993.

BASU, A.K. \& MARNETT, L.J. Unequivocal demonstration that malonaldehyde is a mutagen. Carcinogenesis, 4:331-333, 1983.

BIRD, R.P.; DRAPER, H.H.; BASRUR, P.K. Effect of malonaldehyde and acetaldehyde on cultured mammalian cells. Production of micronuclei and chromosomal aberrations. Mutation Research, 101: 237-246, 1982a.

BIRD, R.P.; DRAPER, H.H.; VALLI, V.C.O. Toxicological evaluation of malonaldehyde: a $12^{\text {th }}$ month study of mice. J. Toxicol. Envirom. Health, 10: 897-905, 1982b.

BROWN, J. E., KHODR, H. HIDER, R. C. Structural dependence of flavonoid interactions with $\mathrm{Cu}^{+2}$ ions: implications for their antioxidant properties. Biochem. J. 330:1173-1178, 1998.

CHEN, Z. Y., CHAN, P. T. Antioxidative activity of green tea catechins in canola oil. Chem. Phys.Lipids. 82(2):163-172. (abstract), 1996. 
CONEGLIAN, S.M. et al. Utilização de antioxidantes nas rações. PUBVET, Londrina, V. 5, N. 5, Ed. 152, Art. 1026, 2011.

CHEN, Z. Y., CHAN, P. T., HO, K. Y. et al. Antioxidant activity of natural flavonoids is governed by number and location of their aromatic hydroxyl groups. Chem. Phys. Lipids. 79(2):157-163, 1996.

CHEVOLLEAU, S., MALLET, J.F., UCCIANI, E., GAMISANS, J., GRUBER, M. Antioxidant activity in leaves of some mediterranean plants. J. Am. Oil Chem. Soc., Champaign, v.69, n.12, p.1269-1271, 1992.

CLUTTON, S. The importance of oxidative stress in apoptosis. Brit. Med. Bull, 53: 662-668, 1997.

DABROWSKI, K.J., SOSULSKI, F.W. Composition of free and hydrolysable phenolic acids in defatted flours of ten oilseeds. J. Agric. Food Chem., Columbus, v.32, n.1, p.128-130, 1984.

DECKER, E.A. \& XU,Z. Minimizing rancidity in Muscle foods. Food Technol., 52(10): 340-348,1998.

DIPLOCK, A.T. Fat soluble vitamins: their Biochemistry and applications. Ed. A.T. Diplock, Heinemann, London, p. 194, 1984.

ECONOMOU, K.D., OREOPOULOU, V., THOMOPOULOS, C.D. Antioxidant activity of some plant extracts of the family labiatae. J. Am. Oil Chem. Soc., Champaign, v.68, n.2, p.109-113, 1991.

EHRICH, M., DRISCOLL, C., LARSEN, C. Ability of ethoxyquin and butylated hydroxytoluene to counteract deleterius effects pf dietary aflatoxin in chicks. Avian Dis. 30(4):802-807, 1986.

EHRICH, M., ACHA, M., LARSEN, C. Interactions and the antioxidant butylated hydroxytoluene in two-week-old chicks. Vet. Res. Commun. 12(4-5):329-333, 1988.

EMPSON, K.L.; LABUZA, J.P.; GRAF, E. Phytic acid as a food antioxidant. J. Food Scie., 56(2): 560-563,1991.

FARKAS, J. K., FLOROS, J. D., LINEBACK, D. S. et al. Oxidation kinetics of menhaden oil with TBHQ. J. Food Sci. 62(3):505-507, 1997.

FERRARI, C. K. B. Oxidação lipídica em alimentos e sistemas biológicos: mecanismos gerais e implicações nutricionais e patológicas. Revista de Nutrição, 11: 3-14, 1998.

FORMICA, J. V., REGELSON, W. Review of the biology of Quercetin and related bioflavonoids. Food Chem. Toxicol. 33(12):1061-1080. (abstract), 1995.

FRANKEL, E.N., HUANG, S.W., AESCHBACH, R., PRIOR, E. Antioxidant activity of a rosemary extract and its constituents, carnosic acid, carnosol and rosmarinic acid in bulk oil and oil-inwater emulsion. J. Agric. Food Chem., Columbus, v.44, p.131-135, 1996.

GRAF, E. \& EATON, J.W. Antioxidants functions of phytic acid. Free Radical Biology \& Medicine, 8: 61-69, 1990.

HABERLAND, M.E.; FLESS, G.M.; SCANU, A.M.; FOGELMAN, A.M. Malondialdehyde modification of lipoprotein produces avid uptake by human monocytemacrophages. J. Biol. Chem., 267:41434151, 1992.

HAILA, K., HEINONEN, M. Action of beta-carotene on purified rapeseed oil during light storage. Food Sci. Tech. 27(6):573-577. (abstract), 1994.

HOULIHAN, C.M., HO, C.T., CHANG, S.S. Elucidation of the chemical structure of novel antioxidant, rosmaridiphenol, isolated from rosemary. J. Am. Oil Chem. Soc., Champaign, v.61, n.6, p.1036-1039, 1984. 
CONEGLIAN, S.M. et al. Utilização de antioxidantes nas rações. PUBVET, Londrina, V. 5, N. 5, Ed. 152, Art. 1026, 2011.

KÄHKÖNEN, M.P., HOPIA, A.I., VUORELA, H.J., RAUHA, J.-P., PIHLAJA, K., KUJALA, T.S., HEINONEN, M. Antioxidant activity of plant extracts containing phenolic compounds. J. Agric. Food Chem., Columbus, v.47, p.3954-3962, 1999.

KIKUZAKI, H., NAKATANI, N. Structure of a new antioxidative phenolic acid from oregano (Origanum vulgare L.). Agric. Biol. Chem., v.53, n.2, p.519- 524, 1989.

LAGOURI, V., BOSKOU, D. Nutrient antioxidants in oregano. Int. J. Food Sci. Nutr., London, v.47, p.493-497, 1996.

LIN, S.S. Fats and oils oxidation, In: WAN, P.J. Introduction to fats and oils technology. Champaign: AOCS,p. 211-231, 1991.

MADSEN, H.L., BERTELSEN, G. Spices as antioxidants. Trends Food Sci. Technol., Oxford, v.6, p.271-277, 1995.

MILOS, M., MASTELIC, J., JERKOVIC, I. Chemical composition and antioxidant effect of glycosidically bound volatile compounds from oregano (Origanum vulgare L. ssp. hirtum). Food Chem., Kidlington, v.71, p.79-83, 2000.

NAKATANI, N. Antioxidants from spices and herbs. In: SHAHIDI, F., ed. Natural antioxidants: chemistry, health effects and applications. Champaign: AOCS Press,p.64-75, 1997.

NAKATANI, N. Natural antioxidants from spices. In: HO, C.T., LEE, C.Y., HUANG, .T., eds. Phenolic compounds in food and their effects on health. Washington: American Chemical Society, p.54-71, 1992.

NATIONAL TOXICOLOGY PROGRAM. "The NTP studies database", (01/07/00), http://ntpserver.niehs.nih.gov, (16/09/04).

OFFORD, E.A., GUILlOT, F., AESCHBACH, R., LÖLIGER, J., PFEIFER, A.M.A. Antioxidant and biological properties of rosemary components: implications for food and health. In: SHAHIDI, F., ed. Natural antioxidants: chemistry, health effects and applications. Champaign: AOCS, Press, p.88-96, 1997.

OHSHIMA, T., YANKAH, V. V., USHIO, H. et al. Antioxidizing potentials of BHA, BHT, TBHQ, tocopherol, and oxygen absorber incorporated in a Ghanaian fermented fish product. Adv. Exp. Med. Biol. 434:181-188. (abstract), 1998.

OOMAH, B.D., KENASCHUK, E.O., MAZZA, G. Phenolic acids in flaxseed. J. Agric. Food Chem., Columbus, v.43, p.2016-2019, 1995.

PARKE, D. V., LEWIS, D. F. Safety aspects of food preservatives. Food Addit. Contam. 9(5):561577. (abstract), 1992.

PASSOTO, J. A., PENTEADO, M. V. C., MANCINI-FILHO, J. Atividade antioxidante do beta-caroteno e da vitamina A. Estudo comparativo com antioxidante sintético. Ciênc. Tecnol. Aliment. 18(1)68-72, 1998.

RAMANATHAN, L., DAS, N.P. Studies on the control of lipid oxidation in ground fish by some polyphenolic natural products. J. Agric. Food Chem.,Columbus, v.40, p.17-21, 1992.

RICE-EVANS, C.A., MILlER, N.J., BOLWELL, P.G., BRAMLEY, P.M., PRIDHAM, J.B. The relative antioxidant activities of plant-derived polyphenolic flavonoids. Free Radical Res., Amsterdam, v.22, n.4, p.375- 383, 1995.

SHAHIDI, F., WANASUNDARA, P.K.J.P.D. Phenolic antioxidants. Crit. Rev. Food Sci. Nutr., Lauderdale, v.32, n.1, p.67-103, 1992. 
CONEGLIAN, S.M. et al. Utilização de antioxidantes nas rações. PUBVET, Londrina, V. 5, N. 5, Ed. 152, Art. 1026, 2011.

SHERWIN, E.R.; THOMPSON, J.W. Tertiary-butylhydroquinone: an antioxidant for fats and oils and fats containing foods. Food Technology. V.21, 912-916,1967.

TSALIKI, E., LAGOURI, V., DOXASTAKIS, G. Evaluation of the antioxidant activity of lupin seed flour and derivatives (Lupinus albus ssp. Graecus). Food Chem., Kidlington, v.65, p.71-75, 1999.

TSIMIDOU, M., BOSKOU, D. Antioxidant activity of essencial oils from the plants of the Lamiaceae family. In: CHARALAMBOUS, G. Spices, herbs and edible fungi. Elsevier: Amsterdam, p.273284, 1994.

VALENZUELA, A. Natural antioxidants: a new perspective for the problems of oxidative rancity of lipids. In: ALLTECH'S ANNUAL SYMPOSIUM, 11, 1995. Proceedings... Nottingham: Nottingham University Press, p.207-220, 1995.

VALENZUELA, A. Natural antioxidants: a new perspective for the problems of oxidative rancity of lipids. In: ALLTECH'S ANNUAL SYMPOSIUM, 11, 1995. Proceedings... Nottingham: Nottingham University Press, p.207-220, 1995.

VONGADOW, A. JOUBERT, E, HANSMANN, C. F. Comparison of the antioxidant activity of aspalathin with that of other plant phenols of rooibos tea (Aspalathus linearis), alphatocopherol, BHT, and BHA. J. Agr. Food Chem. 45(3):632-638. (abstract), 1997.

WANASUNDARA, P.K.J.P.D., SHAHIDI, F., SHUKLA, V.K.S. Endogenous antioxidants from oilseeds and edible oils. Food Rev. Int., v.13, n.2, p.225-292, 1997.

WANASUNDARA, U. N. e SHAHIDI, F. Stabilization of seal blubber and menhaden oils with green tea catechins. J. Amer. Oil Chem. Soc. 73(9):1183-1190. (abstract), 1996.

WISEMAN, $\mathrm{H}$. Dietary influences on membrane function: importance in protection against oxidative damage and disease. J. Nutr. Biochem., v.7, p.2-15, 1996.

WOOLFORD, M. Auto-oxidação e antioxidantes em rações e ingredientes. : Alltech, Inc. 18, sem data.

YANISHLIEVA, N.V., MARINOVA, E.M. Effects of antioxidants on the stability of triacylglycerols and methyl esters of fatty acids of sunflower oil. Food Chem., Kidlington, v.54, p.377-382, 1995.

ZHOU, Jr.; ERDMAN Jr., J.W. Phytic acid in health and disease. Crit. Dev. In Food Sci. Nutr. 35(6): 495-508,1995. 